Article

\title{
Highly Expressed miR-375 is not an Intracellular Oncogene in Merkel Cell Polyomavirus-Associated Merkel Cell Carcinoma
}

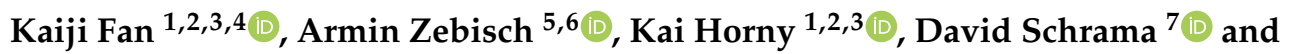 \\ Jürgen C. Becker 1,2,3,8,*(i) \\ 1 Department of Translational Skin Cancer Research, University Hospital Essen, 45141 Essen, Germany; \\ k.fan@dkfz-heidelberg.de (K.F.); k.horny@dkfz-heidelberg.de (K.H.) \\ 2 German Cancer Consortium (DKTK), 45141 Essen, Germany \\ German Cancer Research Center (DKFZ), 69120 Heidelberg, Germany \\ 4 Department of Dermatology, Medical University of Graz, 8010 Graz, Austria \\ 5 Division of Hematology, Medical University of Graz, 8010 Graz, Austria; armin.zebisch@medunigraz.at \\ 6 Otto Loewi Research Center for Vascular Biology, Immunology and Inflammation, Division of Pharmacology, \\ Medical University of Graz, 8010 Graz, Austria \\ 7 Department of Dermatology, University Hospital Würzburg, 97080 Würzburg, Germany; \\ schrama_d@ukw.de \\ 8 Department of Dermatology, University Hospital Essen, 45147 Essen, Germany \\ * Correspondence: j.becker@dkfz.de; Tel.: +49-201-1836-727
}

Received: 6 January 2020; Accepted: 24 February 2020; Published: 25 February 2020

check for updates

\begin{abstract}
R-375 is a highly abundant miRNA in Merkel cell carcinoma (MCC). In other cancers, it acts as either a tumor suppressor or oncogene. While free-circulating miR-375 serves as a surrogate marker for tumor burden in patients with advanced MCC, its function within MCC cells has not been established. Nearly complete miR-375 knockdown in MCC cell lines was achieved using antagomiRs via nucleofection. The cell viability, growth characteristics, and morphology were not altered by this knockdown. miR-375 target genes and related signaling pathways were determined using Encyclopedia of RNA Interactomes (ENCORI) revealing Hippo signaling and epithelial to mesenchymal transition (EMT)-related genes likely to be regulated. Therefore, their expression was analyzed by multiplexed qRT-PCR after miR-375 knockdown, demonstrating only a limited change in expression. In summary, highly effective miR-375 knockdown in classical MCC cell lines did not significantly change the cell viability, morphology, or oncogenic signaling pathways. These observations render miR-375 an unlikely intracellular oncogene in MCC cells, thus suggesting that likely functions of miR-375 for the intercellular communication of MCC should be addressed.
\end{abstract}

Keywords: miR-375; antagomiRs; Merkel cell carcinoma; Hippo signaling; focal adhesion

\section{Introduction}

Merkel cell carcinoma (MCC) is an aggressive skin cancer. Risk factors for MCC include an advanced age, ultraviolet (UV) light exposure, and immune suppression [1]. About $80 \%$ of MCC tumors are associated with genomic integration of the Merkel cell polyomavirus (MCPyV) bearing truncating tumor-specific large T antigen mutations, while the others are characterized by a UV-induced tumor mutational burden [1]. The pathogenesis of these two types of MCC tumors is surmised to be distinct: MCPyV-positive MCC is associated with MCPyV T antigen-mediated tumor suppressor gene inhibition and/or oncogene induction [1-3], while in MCPyV-negative MCC tumors, the comparable 
oncogenic observations are caused by UV-induced DNA mutations [1,4-6]. However, the specific molecular alterations caused by either MCPyV or UV-mutations are just starting to emerge $[7,8]$.

Transcription factor Atonal homolog 1 is characterized as a lineage-dependency oncogene in MCC, which induces miR-375 expression [9]. microRNAs (miRNAs) are small, 21nt single-stranded RNAs, which post-transcriptionally regulate the stability and translation of genes, mainly by binding to the 3' UTR of mRNAs [10,11]. Each miRNA can bind a specific set of genes, which are referred to as its target genes. The dysregulation of miRNAs has been reported in almost all types of human cancer [10,12]. miRNA expression profiling in MCCs revealed miR-375 as one of the most abundant miRNAs in classical MCC cell lines and tumor tissues [13-16]. Physiologically, miR-375 acts as a pancreatic-islet miRNA essential for $\beta$-cell formation and the regulation of insulin secretion $[17,18]$. Divergent miR-375 expression has been described for multiple cancer types, e.g., reduced expression in gastric [19,20], pancreatic [21], colon [22,23], and liver cancer [24], and high expression in medullary thyroid carcinoma [25], prostate cancer [26], and MCC [13-16]. Therefore, miR-375 was assumed to be an oncogenic miRNA in the latter group.

However, when the function of miR-375 in MCC was studied by different groups, the results were inconsistent. Abraham et al. reported that miR-375 was involved in neuroendocrine differentiation and miR-375 knockdown in classical MCC cell lines (MKL-1 and MS-1) and did not alter their growth properties [13]. Our preliminary results of miR-375 knockdown experiments were consistent with their report for the tested MCC cell lines [9]. In contrast, Kumar et al. reported that miR-375 inhibition in WaGa and MKL-1 cells reduced cell growth and induced apoptosis by targeting lactate dehydrogenase $\mathrm{b}(L D H B)$ [27]. Recent reports from the same group showed that miR-375, together with other miRNAs, inhibits autophagy, thus protecting MCC cells from autophagy-associated cell death [28]. To resolve these controversies, here, we scrutinize the function of miR-375 in MCC. For this, we established a highly efficient method for miR-375 knockdown in classical MCC cell lines and analyzed the inflected effects, with an emphasis on intracellular signaling.

\section{Results}

\subsection{Effective Knockdown of miR-375 by Nuclear Transfection Using miR-375 AntagomiRs}

To explore the function of miRNAs, it is essential to achieve largely complete knockdown. Achieving highly effective knockdown in classical MCC cell lines is trivial. Therefore, we tested different transfection methods, i.e., lipofectamine and nucleofection, in the two classical MCC cell lines WaGa and PeTa using miR-375 antagomiRs.

The transfection of miR-375 antagomiRs by lipofectamine reduced miR-375 expression in a dose-dependent manner, but was not sufficient for complete knockdown of the highly expressed miR-375 (Figure 1a,b). Next, we performed nucleofection and optimized the transfection conditions. Program D23 with 25nM miR-375 antagomiRs was determined as the optimal protocol for knockdown, which rendered dramatically reduced miR-375 expression in both WaGa and PeTa cells (Figure 1c,d and Figure S1). All further experiments were carried out using these conditions. 
a

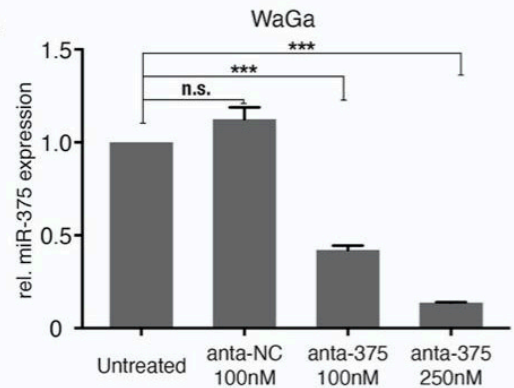

C

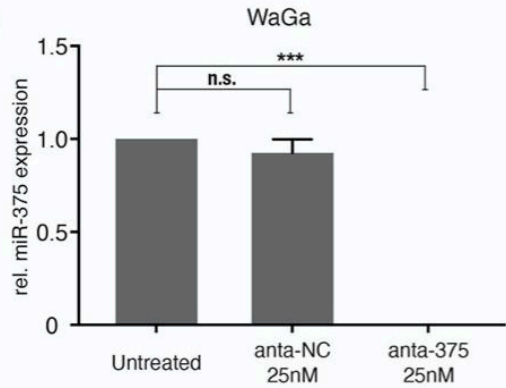

b

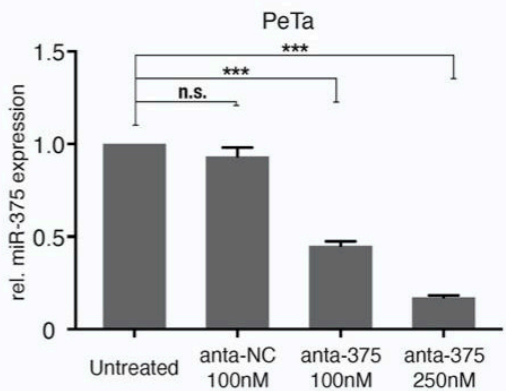

d

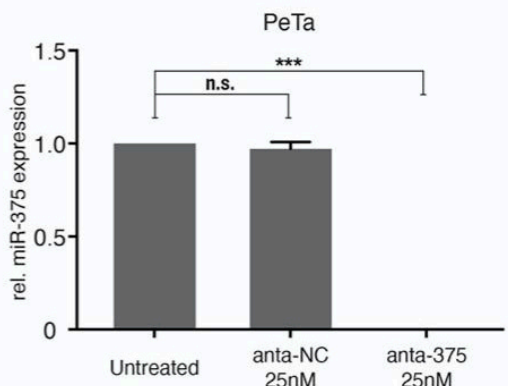

Figure 1. Knockdown of miR-375 in classical Merkel cell carcinoma (MCC) cell lines. Relative miR-375 expression was determined in triplicate by qRT-PCR in WaGa $(\mathbf{a}, \mathbf{c})$ and $\mathrm{PeTa}(\mathbf{b}, \mathbf{d})$ cells transfected with miR-375 antagomiRs (anta-375) or a negative control (anta-NC) using lipofectamine (top row; $\mathbf{a}, \mathbf{b}$ ) or nucleofection (bottom row; c,d). Quantification cycle threshold (Cq) values were normalized to the small nucleolar RNA RNU6B (U6) and calibrated to the untreated WaGa cells. All experiments were independently repeated three times. Error bars represent SD, ${ }^{* * *}$ indicates $p<0.001$. n.s.: non-significant.

\section{2. miR-375 Knockdown Does Not Impact the Morphology, Proliferative Capacity, or Apoptosis of MCC Cells}

We were able to confirm our previous observation that miR-375 knockdown has no major impact on cell proliferation, survival, growth characteristics, or cell morphology (Figure 2 and Figures S2 and S3). Notably, even the highly effective miR-375 knockdown did not alter the morphologic appearance as cells still showed a neuroendocrine growth pattern as loose spheroids or single cells, which was identical to the growth pattern in cells transfected with unspecific control antagomiRs (Figure 2a,b). Furthermore, neither the metabolic nor proliferative activity was affected by the miR-375 knockdown (Figure 2c,d). While the harsh transfection conditions for the highly efficient miR-375 knockdown inhibited the proliferation of MCC cells per se, we observed around $40 \%$ apoptotic cells $24 \mathrm{~h}$ after nucleofection in both WaGa and PeTa, and no difference was observed in MCC cells transfected with miR-375 antagomiRs or the negative control (Figure 2e,f and Figure S3). Sequential analyses on days 3 and 5 after transfection further supported that miR-375 knockdown had no specific impact on cell survival or metabolic activity (Figure 2c-f and Figure S3). 
a

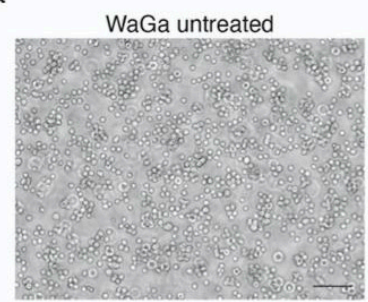

WaGa anta-NC $120 \mathrm{~h}$

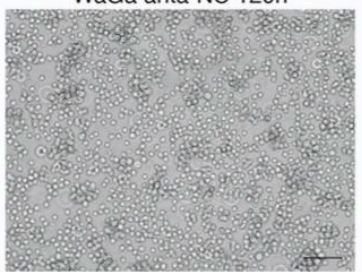

PeTa anta-NC 120h

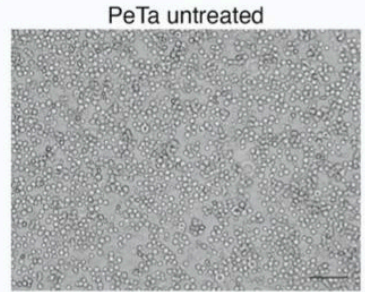

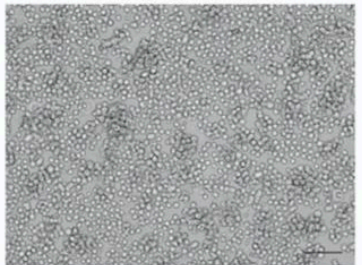

WaGa anta-375 120h

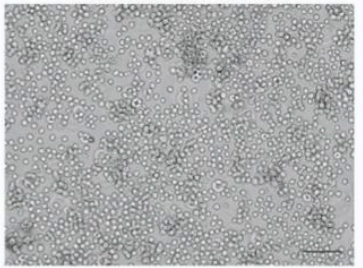

PeTa anta-375 120h

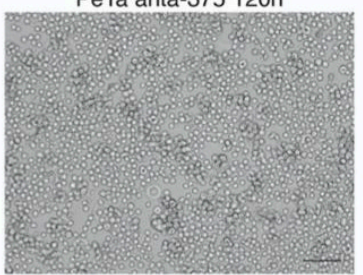

C
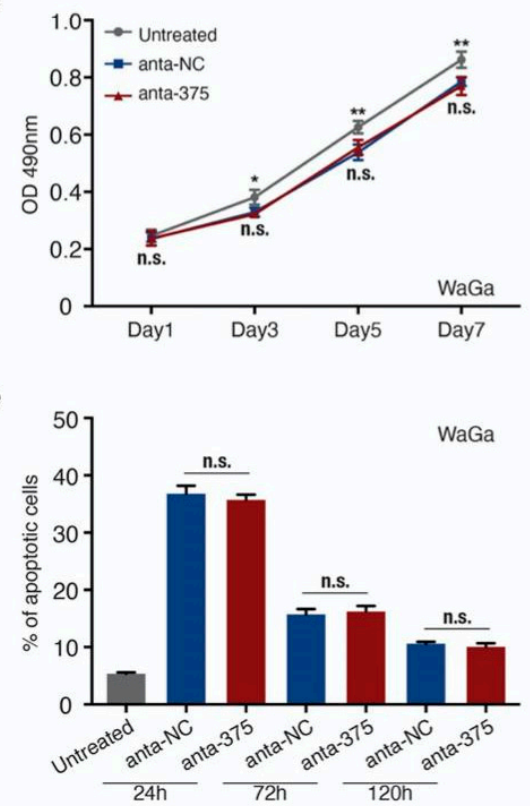

d

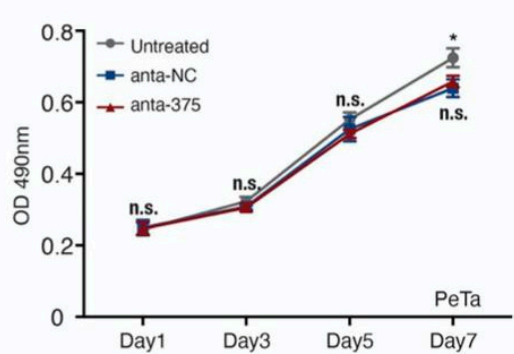

f

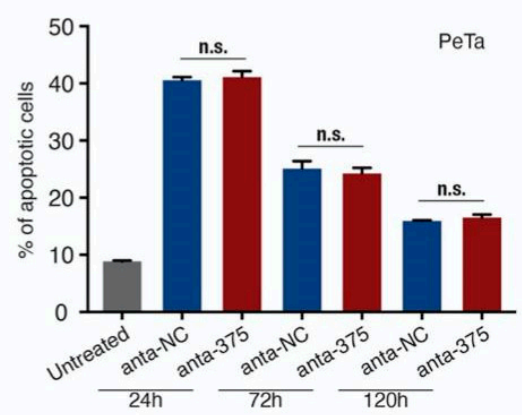

Figure 2. miR-375 knockdown does not alter the cell morphology, viability, and apoptosis of MCC cells. (a,b) Morphology of WaGa (a) and PeTa (b) cells, untransfected (untreated) and $120 \mathrm{~h}$ after nucleofection with either anta-NC or anta-375. (c,d) Cell proliferation (metabolic activity) of WaGa (c) and PeTa (d) cells after nucleofection with miR-375 antagomiRs or a negative control was measured by MTS assays at the indicated time points. Absorbance values at $490 \mathrm{~nm}$ are presented. Scale bar: $100 \mu \mathrm{M}$. (e,f) The apoptotic cell rate of untreated or nuclear transfected WaGa (e) and PeTa (f) cells was determined by flow cytometry using the NucView 488/ MitoView 633 apoptosis assay. Scale bar represents $50 \mu \mathrm{m}$. All experiments were independently repeated three times, error bars represent $\mathrm{SD}$, * indicates $p<0.05$, and ${ }^{* *}$ indicates $p<0.01$. n.s.: non-significant.

\section{3. miR-375 Target Genes are Involved in Hippo- and EMT-Related Signaling Pathways}

To further investigate the role of miR-375 in MCCs, we predicted target genes of this miRNA using the miRNA target prediction tool ENCORI. This tool has the advantage that the results can be filtered for experimentally-validated target genes. Nevertheless, more than 3000 target genes were predicted; thus, the top 500 ranked genes were selected for further analysis (Table S1). Gene Ontology (GO) analysis showed that miR-375 target genes contribute to several signaling pathways, including Golgi transport, cell junction assembly, Hippo signaling, and neuron differentiation (Figure 3a). To test the relevance of 
these predictions in MCC, we re-analyzed previously published transcriptome microarray data of MCC cell lines [29]. Of this data set, four MCC cell lines were selected according to their miR-375 expression level: WaGa and MKL-1 with high and, MCC13 and MCC26 with low, miR-375 expression [14]. Gene Set Enrichment Analysis (GSEA) confirmed that particularly genes related to the focal adhesion signaling pathway were lower expressed in cell lines with high miR-375 expression (Figure 3b). Moreover, focal adhesion signaling pathways included most of the experimentally-confirmed miR-375 target genes; this notion also applies for miR-375 target genes related to the Hippo signaling pathway. Both pathways regulate epithelial to mesenchymal transition (EMT) [30] (Figure 3c).

a

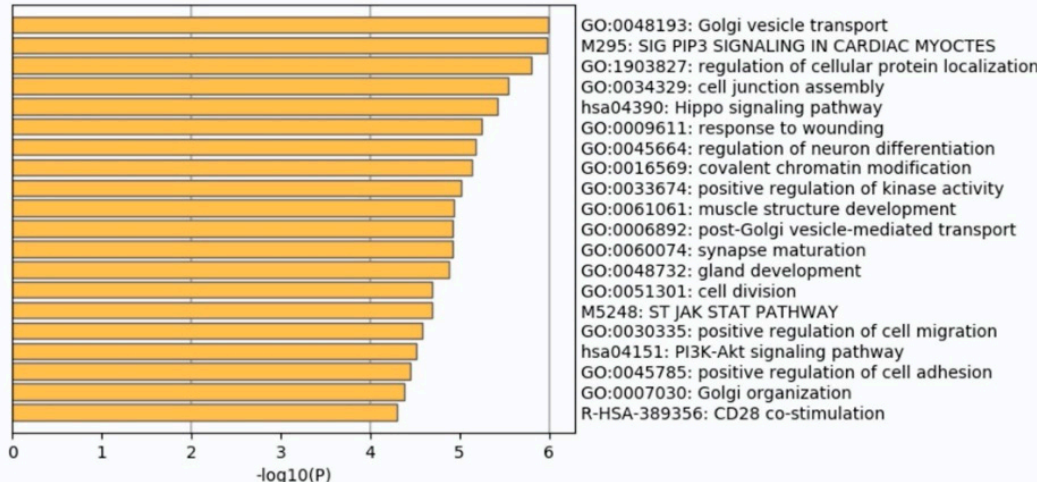

b

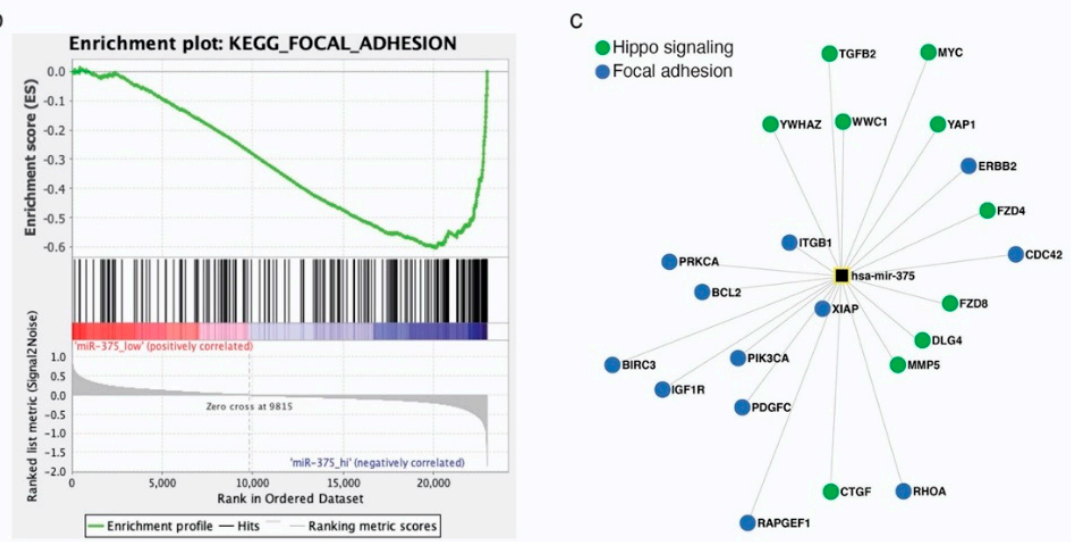

Figure 3. miR-375 target genes are involved in Hippo and epithelial to mesenchymal transition (EMT) signaling pathways in MCC cells. (a) Gene ontology analysis was performed in Metascape using the top 500 predicted miR-375 target genes. (b) Gene set enrichment analysis was performed using previously published transcriptome microarray data of MCC cell lines with high (WaGa and MKL1) and low (MCC13 and MCC26) miR-375 expression. Enrichment plot of the kegg_focal_adhesion signaling pathway is depicted. (c) miR-375 target genes involved in Hippo and focal adhesion signaling pathways.

\subsection{Hippo and EMT Signaling Pathway-Related Genes are Marginally Altered by miR-375 Knockdown}

Since our in-silico analysis suggested that miR-375 may regulate Hippo- and EMT-related signaling pathways, we tested this hypothesis by miR-375 knockdown experiments, together with qRT-PCR-based expression arrays for Hippo and EMT signaling-related genes. These experiments, however, did not reveal any statistically significant changes in the gene expression of compounds of these two signaling pathways in MCC cell lines upon miR-375 knockdown. Specifically, miR-375 knockdown only resulted in a non-significant (i.e., less than +/- two-fold change in expression) upregulation of eleven genes $(11 / 84,13.1 \%)$ and downregulation of four genes $(4 / 84,4.8 \%)$ related to the Hippo signaling pathway, as well as a non-significant upregulation of eleven genes (11/84, 13.1\%) and downregulation of three genes $(3 / 84,3.5 \%)$ with respect to the EMT-signaling pathway (Figure 4, Table S2). 
a
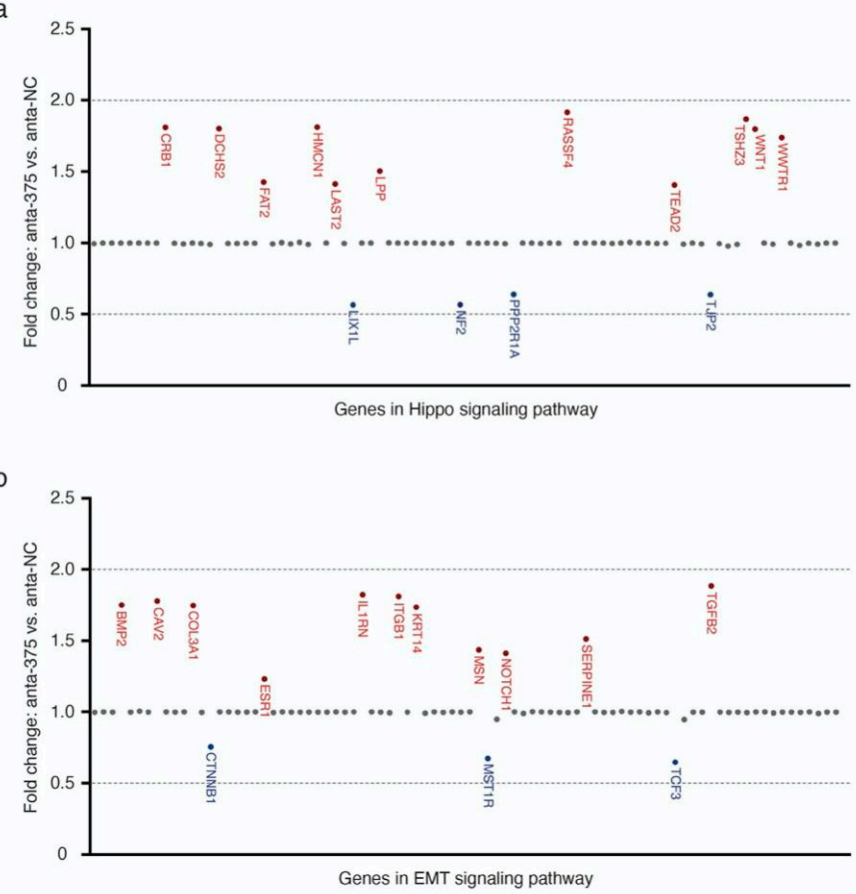

Figure 4. Moderate changes in the expression of Hippo (a) and EMT (b) signaling pathway-related genes by miR-375 knockdown.

The expression of genes related to Hippo (a) and EMT (b) signaling pathways was determined by a multiplexed qRT-PCR expression array in WaGa cells transfected with anta-375 or anta-NC, normalized to the average Cq values of housekeeping genes (GAPDH, HPRT, and RPLP0) and calculated for the $\Delta \mathrm{Cq}$ of WaGa cells transfected with anta-NC. Gene names colored in red represent genes upregulated upon miR-375 knockdown, while gene names colored in blue represent downregulated genes. Doted lines represent $+/$ - two-fold changes. Experiments were independently repeated twice.

\section{Discussion}

Despite the fact that miR-375 is highly expressed in classical MCC cell lines and MCC tumors, its function in MCC is not clear. To study the relevance of miR-375 in intracellular signaling in detail, we performed a series of knockdown experiments using specific antagomiRs. Surprisingly, even the nearly complete knockdown of miR-375 expression did not affect the proliferation, growth pattern, or cell morphology. Similarly, the impact of miR-375 knockdown on the expression of Hippo and EMT signaling pathway-related genes, i.e., pathways predicted to be regulated by miR-375, was only marginal. These results, taken together with our previous observations that miR-375 is present in MCC cell line-conditioned medium in sera of preclinical xenotransplantation animal models and in sera of MCC patients [14], suggest that miR-375 may serve intercellular rather than intracellular signaling in MCC. Indeed, miR-375 was recently characterized as an exosomal shuttle miRNA [31,32].

In previous reports, miR-375 knockdown or inhibition in MCC cell lines resulted in different consequences. miR-375 knockdown using antagomiRs did not alter growth properties [13], whereas the inhibition of miR-375 using an miRNA sponge suppressed cell growth and induced cell death via downregulation of the $L D H B$ gene [27]. Recently, the same group demonstrated that miR-375 inhibits autophagy to protect MCC cells from cell death [28]. AntagomiRs bind particular miRNAs, causing their degradation, while sponge RNAs compete with target mRNAs. Differences in the specificity and/or effectivity of the used methods are likely to explain some of the conflicting results. The quantification of miRNA expression after miR-375 knockdown by antagomiRs might be helpful to better understand this controversy. Notably, miR-375 is lowly expressed in variant MCC cell lines 
and the ectopic expression of miR-375 decreased their cell viability and migratory potential [13,27], suggesting that miR-375 might be a tumor suppressor in these cells. However, several reports question if these variant MCC cell lines are indeed representative of MCC tumors [29,33].

The knockdown of abundant miRNAs can be challenging [34]. AntagomiRs have been employed for miRNA silencing in vitro and in vivo via miRNA degradation for years $[34,35]$. In our study, we introduced the respective antagomiRs with two different transfection conditions, which revealed that nuclear transfection was much more efficient and only this method succeeded in nearly complete knockdown up to five days post-transfection. To be noted, we observed a slight increase in miR-375 expression over time after antagomiRs transfection. Therefore, the described method is very effective for short-term knockdown, but not for long-term inhibition (Figure S2). Besides miRNA antagomiRs, the miRNA sponge is another powerful tool that can be employed to inhibit the miRNA function. Notably, an miRNA sponge was used by Kumar et al. to inhibit the miR-375 function in MCC cells [27]. To achieve long-term miRNA inhibition, viral vectors based on stable miRNA antagomiRs or sponge expression and CRISPR-mediated miRNA knockout are feasible [36-38].

By testing for the expression of Hippo and EMT signaling pathway-related genes after miR-375 knockdown, we observed moderate expression changes of only a few genes. Furthermore, even these changes did not clearly reveal any relevant role of miR-375 in regulating these pathways. Indeed, both EMT-negative (CAV2 and IL1RN) and -positive (BMP2, ITGB1, and TGFB2) regulators were induced upon miR-375 knockdown. Therefore, miR-375 may inhibit or induce EMT in MCC cells. More importantly, none of the changes were greater than two-fold. The gap between the predicted and functional observed effects of miR-375 knockdown is not entirely unexpected. Several reports have provided a possible explanation: long non-coding RNAs, such as TINCR, HNGA1, and CircFAT1, act as an miR-375 sponge [39-41]. Alternatively, other miRNAs in MCC may have redundant functional targets as miR-375 [42].

In summary, we have demonstrated that even the highly efficient, almost complete knockdown of the highly abundant miR-375 in classical MCC cells lines, has no relevant impact on the cell viability, metabolic activity, morphology, or oncogenic signaling pathways targeted by miR-375. These observations render miR-375 unlikely to function as an intracellular oncogene in MCC cells.

\section{Materials and Methods}

\subsection{Cell Culture}

The classical, MCPyV-positive MCC cell lines WaGa and PeTa were maintained in RPMI-1640 (PAN Biotech, Aidenbach, Germany) supplemented with 10\% fetal bovine serum (Sigma-Aldrich, Munich, Germany) and 1\% penicillin/streptomycin (Biochrome, Berlin, Germany), as previously described [43].

\section{2. miR-375 Knockdown}

For miR-375 knockdown, specific miR-375 inhibitors (Assay ID: MH10327, Catalog: 4464084, Thermo Fisher Scientific, Frankfurt, Germany) or respective controls (Catalog: 4464076, Thermo Fisher Scientific) were used.

For the transfection of MCC cells, two methods were compared. Lipofectamine 3000 reagent (Thermo Fisher Scientific) was used according to the instructions of the manufacturer, i.e., $2 \times 10^{6}$ cells were seeded into a 6-well-plate $24 \mathrm{~h}$ before transfection with $100 \mathrm{nM}$ or $250 \mathrm{nM}$ of antagomiRs. Alternatively, the Nucleofector ${ }^{\mathrm{TM}} 2 \mathrm{~b}$ Device (Lonza, Basel, Switzerland) with the Cell Line Nucleofector ${ }^{\circledR}$ Kit V (Lonza) was used. D-23 was established as the appropriate program to transfect MCC cells (https://bioscience.lonza.com/lonza_bs/CH/en/nucleofector-technology). A total of $100 \mu \mathrm{L}$ of buffer $\mathrm{V}$ was mixed with $10 \mu \mathrm{L}$ miRNA antagomiRs $(25 \mathrm{nM})$ and $2 \times 10^{6} \mathrm{MCC}$ cells before being transferred into an electroporation cuvette. After the pulse, cells were immediately transferred into 6-well-plates containing pre-warmed culture media. 


\section{3. $q R T-P C R$ for $m i R-375$}

Applied Biosystems TaqMan MicroRNA assays (Thermo Fisher Scientific) were performed according to the manufacturer's instructions. Pre-designed TaqMan microRNA assays for miR-375 (ID000564) were used. The quantification cycle threshold (Cq) values of miR-375 were normalized to the small nucleolar RNA RNU6B (ID001093) and the relative expression of the respective comparator was calculated using the $2-\Delta \Delta \mathrm{Cq}$ method.

\subsection{MTS Assay}

Dead cells and cell debris after nucleofection were removed using Ficoll-mediated gradient centrifugation (Biochrom, Berlin, Germany). For MTS assays, $10^{4}$ living cells per well of each group (untreated, anta-NC and anta-375) were seeded into 96-well-plates. CellTiter 96 AQueous One Solution (Promega, Walldorf, Germany) was used to determine the relative cell proliferation every other day. In brief, $20 \mathrm{uL}$ of the CellTiter solution was added to each well and incubated for two hours, and the absorbance was then measured using a plate reader at $490 \mathrm{~nm}$.

\subsection{Apoptosis Assay}

The NucView 488/MitoView 633 apoptosis assay kit (Biotium, Fremont, CA, USA) was used to determine the apoptotic cell rate, according to the manufacturer's instruction. Viable cells were stained red with MitoView 633 (red, APC-A channel), and apoptotic cells were stained green with NucView 488 (green, PE-A channel). Twenty-four hours' post-nucleofection and subsequently every other day, cells were analyzed using a CytoFLEX flow cytometer (Beckman Coulter, Krefeld, Germany).

\subsection{Prediction of miR-375 Target Genes, Gene Ontology (GO), and Gene Set Enrichment Analysis (GSEA)}

The Encyclopedia of RNA Interactomes (ENCORI, http://starbase.sysu.edu.cn/index.php) provides miRNA-target gene interactions, which are based on miRNA target prediction programs, i.e., TargetScan, miRanda, microT, PITA, miRmap, and PicTar. All miRNA target predictions are supported by published Argonaute-crosslinking and immunoprecipitation (AGO-CLIP) data [44]. Predicted target genes are ranked based on the predicted efficacy of targeting, as calculated using cumulative weighted context++ scores of the sites and related AGO-CLIP scores (clipExpNum, Table S1) [44,45]. The top 500 highest ranking predicted target genes were selected for the following analysis.

Metascape (http://metascape.org) was applied for GO analysis [46]. Metascape incorporates a core set of default ontologies, including GO processes, KEGG pathways, Reactome gene sets, canonical pathways, and CORUM complexes, for enrichment analysis.

GSEA, the desktop application from the MSigDB of Broad Institute (Cambridge, MA, USA), was used for re-analysis of the transcriptome microarray of selected MCC cell lines (http://software. broadinstitute.org/gsea/msigdb/index.jsp) [47]. The transcriptome microarray data set GSE50451 was downloaded from Gene Expression Omnibus. Four MCC cell lines were selected and analyzed in GSEA: WaGa and MKL-1 as miR-375_high, and MCC13 and MCC26 as miR-375_low.

\subsection{Pathway Finder Gene Expression Arrays}

The RT2 Profiler PCR arrays (SABioscience via Qiagen, Hilden, Germany) for epithelial to mesenchymal transition (EMT) (PAHS-090Z) and Hippo signaling (PAHS-172Z) were performed according to the manufacturer's instructions. Total RNA was isolated from MCC cell lines three days after nucleofection with miR-375 inhibitors or the respective control. A total of 200ng of total RNA was transcribed into cDNA using the RT2 first strand kit (Qiagen). The relative gene expression was determined using the $\mathrm{RT}^{2}$ Profiler PCR Array software from Qiagen (https://dataanalysis.qiagen.com/ pcr/arrayanalysis.php). 


\subsection{Statistical Analysis}

Statistical analyses were performed using GraphPad Prism 8.0 Software (GraphPad Software Inc., San Diego, CA, USA). Experiments containing more than two groups were analyzed using the Kruskal-Wallis test, and an unpaired nonparametric ANOVA. R studio (version 3.6.0) was used in the statistical analysis as indicated: the ggpubr R package (version 3.2.0) for the dot plot of gene expression in EMT and Hippo signaling. A $p$-value smaller than 0.05 was considered significant; the respective $\mathrm{p}$-values are indicated in the figures as follows: ${ }^{*} p<0.05,{ }^{* *} p<0.01$, and ${ }^{* *} p<0.001$.

\section{Conclusions}

The highly efficient knockdown of abundant miR-375 achieved by miR-375 antagomiRs with nucleofection did not cause obvious effects on the cell viability, apoptosis, morphology, or oncogenic Hippo- and EMT-related signaling pathways. These observations render miR-375 unlikely to function as an intracellular oncogene in MCC cells.

Supplementary Materials: The following are available online at http://www.mdpi.com/2072-6694/12/3/529/s1, Figure S1: Expression of miR-375 and U6 in MCC cells transfected with antagomiRs, depicted in amplification curves, Figure S2: Relative expression of miR-375 in MCC cells transfected with antagomiRs, Figure S3: Apoptosis of MCC cells transfected with antagomiRs was determined in flow cytometry, Table S1: List of predicted miR-375 target genes in ENCORI, Table S2: Alteration of gene expression (Hippo and EMT related) after miR-375 knockdown in WaGa cells.

Author Contributions: Conceptualization, J.C.B.; methodology, K.F., D.S., and A.Z.; formal analysis, K.F. and K.H.; investigation, K.F. and A.Z.; resources, A.Z. and J.C.B.; data curation, K.F. and K.H.; writing, K.F., K.H., and J.C.B.; visualization, K.F.; supervision, J.C.B. and D.S.; project administration, J.C.B.; funding acquisition, J.C.B. All authors have read and agreed to the published version of the manuscript.

Funding: This research was funded by the European Commission, Grant Agreement number HEALTH-F2-2012-277775, IMMOMEC.

Acknowledgments: We thank Ashwin Sriram, TSCR, DKTK site University of Essen, Essen, Germany and the DKFZ, Heidelberg, Germany for critically reading the final version of the manuscript.

Conflicts of Interest: J.C. Becker is receiving speaker's bureau honoraria from Amgen, Pfizer, MerckSerono, and Sanofi, and is a paid consultant/advisory board member for eTheRNA, MerckSerono, Pfizer, 4SC, REcordati, InProTher, and Sanofi. His group receives research grants from IQVIA, Merck Serono, and Alcedis. None of the activities are related to the submitted work. None of the other authors indicated any potential conflicts of interest.

\section{References}

1. Becker, J.C.; Stang, A.; DeCaprio, J.A.; Cerroni, L.; Lebbe, C.; Veness, M.; Nghiem, P. Merkel cell carcinoma. Nat. Rev. Dis. Primers 2017, 3, 17077. [CrossRef] [PubMed]

2. Arora, R.; Shuda, M.; Guastafierro, A.; Feng, H.C.; Toptan, T.; Tolstov, Y.; Normolle, D.; Vollmer, L.L.; Vogt, A.; Domling, A.; et al. Survivin is a therapeutic target in Merkel cell carcinoma. Sci. Transl. Med. 2012, 4, 133 ra56. [CrossRef]

3. Hesbacher, S.; Pfitzer, L.; Wiedorfer, K.; Angermeyer, S.; Borst, A.; Haferkamp, S.; Scholz, C.J.; Wobser, M.; Schrama, D.; Houben, R. RB1 is the crucial target of the Merkel cell polyomavirus Large T antigen in Merkel cell carcinoma cells. Oncotarget 2016, 7, 32956-32968. [CrossRef]

4. Wong, S.Q.; Waldeck, K.; Vergara, I.A.; Schroder, J.; Madore, J.; Wilmott, J.S.; Colebatch, A.J.; De Paoli-Iseppi, R.; Li, J.; Lupat, R.; et al. UV-associated mutations underlie the etiology of MCV-negative Merkel cell carcinomas. Cancer Res. 2015, 75, 5228-5234. [CrossRef] [PubMed]

5. Gonzalez-Vela, M.D.C.; Curiel-Olmo, S.; Derdak, S.; Beltran, S.; Santibanez, M.; Martinez, N.; Castillo-Trujillo, A.; Gut, M.; Sanchez-Pacheco, R.; Almaraz, C.; et al. Shared oncogenic pathways implicated in both virus-positive and UV-Induced Merkel cell carcinomas. J. Investig. Derm. 2017, 137, 197-206. [CrossRef] [PubMed]

6. Rozenblatt-Rosen, O.; Deo, R.C.; Padi, M.; Adelmant, G.; Calderwood, M.A.; Rolland, T.; Grace, M.; Dricot, A.; Askenazi, M.; Tavares, M.; et al. Interpreting cancer genomes using systematic host network perturbations by tumour virus proteins. Nature 2012, 487, 491-495. [CrossRef] 
7. Veija, T.; Sarhadi, V.K.; Koljonen, V.; Bohling, T.; Knuutila, S. Hotspot mutations in polyomavirus positive and negative Merkel cell carcinomas. Cancer Genet. 2016, 209, 30-35. [CrossRef]

8. Knepper, T.C.; Montesion, M.; Russell, J.S.; Sokol, E.S.; Frampton, G.M.; Miller, V.A.; Albacker, L.A.; McLeod, H.L.; Eroglu, Z.; Khushalani, N.I.; et al. The genomic landscape of Merkel cell carcinoma and clinicogenomic biomarkers of response to immune checkpoint Inhibitor therapy. Clin. Cancer Res. 2019, 25, 5961-5971. [CrossRef]

9. Fan, K.; Gravemeyer, J.; Ritter, C.; Rasheed, K.; Gambichler, T.; Moens, U.; Shuda, M.; Schrama, D.; Becker, J.C. $\mathrm{MCPyV}$ large $\mathrm{T}$ antigen-induced Atonal homolog 1 is a lineage-dependency oncogene in Merkel cell carcinoma. J. Investig. Derm. 2020, 140, 56-65. [CrossRef]

10. Gebert, L.F.R.; MacRae, I.J. Regulation of microRNA function in animals. Nat. Rev. Mol. Cell Bio. 2019, 20, 21-37. [CrossRef]

11. Lagos-Quintana, M.; Rauhut, R.; Lendeckel, W.; Tuschl, T. Identification of novel genes coding for small expressed RNAs. Science 2001, 294, 853-858. [CrossRef] [PubMed]

12. Peng, Y.; Croce, C.M. The role of MicroRNAs in human cancer. Signal. Transduct. Tar. 2016, 1, 15004. [CrossRef] [PubMed]

13. Abraham, K.J.; Zhang, X.; Vidal, R.; Pare, G.C.; Feilotter, H.E.; Tron, V.A. Roles for miR-375 in neuroendocrine differentiation and tumor suppression via Notch pathway suppression in Merkel cell carcinoma. Am. J. Pathol. 2016, 186, 1025-1035. [CrossRef]

14. Fan, K.; Ritter, C.; Nghiem, P.; Blom, A.; Verhaegen, M.E.; Dlugosz, A.; Odum, N.; Woetmann, A.; Tothill, R.W.; Hicks, R.J. Circulating cell-free miR-375 as surrogate marker of tumor burden in Merkel cell carcinoma. Clin. Cancer Res. 2018, 24, 5873-5882. [CrossRef]

15. Renwick, N.; Cekan, P.; Masry, P.A.; McGeary, S.E.; Miller, J.B.; Hafner, M.; Li, Z.; Mihailovic, A.; Morozov, P.; Brown, M.; et al. Multicolor microRNA FISH effectively differentiates tumor types. J. Clin. Investig. 2013, 123, 2694-2702. [CrossRef]

16. Xie, H.; Lee, L.; Caramuta, S.; Hoog, A.; Browaldh, N.; Bjornhagen, V.; Larsson, C.; Lui, W.O. MicroRNA expression patterns related to Merkel cell polyomavirus infection in human Merkel cell carcinoma. J. Investig. Derm. 2014, 134, 507-517. [CrossRef]

17. Poy, M.N.; Eliasson, L.; Krutzfeldt, J.; Kuwajima, S.; Ma, X.; Macdonald, P.E.; Pfeffer, S.; Tuschl, T.; Rajewsky, N.; Rorsman, P.; et al. A pancreatic islet-specific microRNA regulates insulin secretion. Nature 2004, 432, 226-230. [CrossRef]

18. Poy, M.N.; Hausser, J.; Trajkovski, M.; Braun, M.; Collins, S.; Rorsman, P.; Zavolan, M.; Stoffel, M. miR-375 maintains normal pancreatic alpha- and beta-cell mass. Proc. Natl. Acad. Sci. USA 2009, 106, 5813-5818. [CrossRef]

19. Ding, L.; Xu, Y.; Zhang, W.; Deng, Y.; Si, M.; Du, Y.; Yao, H.; Liu, X.; Ke, Y.; Si, J.; et al. MiR-375 frequently downregulated in gastric cancer inhibits cell proliferation by targeting JAK2. Cell Res. 2010, 20, 784-793. [CrossRef]

20. Tsukamoto, Y.; Nakada, C.; Noguchi, T.; Tanigawa, M.; Lam, T.N.; Uchida, T.; Hijiya, N.; Matsuura, K.; Fujioka, T.; Seto, M.; et al. MicroRNA-375 is downregulated in gastric carcinomas and regulates cell survival by targeting PDK1 and 14-3-3 zeta. Cancer Res. 2010, 70, 2339-2349. [CrossRef]

21. Zhou, J.; Song, S.D.; Cen, J.N.; Zhu, D.M.; Li, D.C.; Zhang, Z.X. MicroRNA-375 is downregulated in pancreatic cancer and inhibits cell proliferation in vitro. Oncol. Res. 2012, 20, 197-203. [CrossRef] [PubMed]

22. Dai, X.; Chiang, Y.; Wang, Z.; Song, Y.; Lu, C.; Gao, P.; Xu, H. Expression levels of microRNA-375 in colorectal carcinoma. Mol. Med. Rep. 2012, 5, 1299-1304. [PubMed]

23. Faltejskova, P.; Svoboda, M.; Srutova, K.; Mlcochova, J.; Besse, A.; Nekvindova, J.; Radova, L.; Fabian, P.; Slaba, K.; Kiss, I.; et al. Identification and functional screening of microRNAs highly deregulated in colorectal cancer. J. Cell Mol. Med. 2012, 16, 2655-2666. [CrossRef] [PubMed]

24. He, X.X.; Chang, Y.; Meng, F.Y.; Wang, M.Y.; Xie, Q.H.; Tang, F.; Li, P.Y.; Song, Y.H.; Lin, J.S. MicroRNA-375 targets AEG-1 in hepatocellular carcinoma and suppresses liver cancer cell growth in vitro and in vivo. Oncogene 2012, 31, 3357-3369. [CrossRef]

25. Hudson, J.; Duncavage, E.; Tamburrino, A.; Salerno, P.; Xi, L.; Raffeld, M.; Moley, J.; Chernock, R.D. Overexpression of miR-10a and miR-375 and downregulation of YAP1 in medullary thyroid carcinoma. Exp. Mol. Pathol. 2013, 95, 62-67. [CrossRef] [PubMed] 
26. Szczyrba, J.; Nolte, E.; Wach, S.; Kremmer, E.; Stohr, R.; Hartmann, A.; Wieland, W.; Wullich, B.; Grasser, F.A. Downregulation of Sec23A protein by miRNA-375 in prostate carcinoma. Mol. Cancer Res. 2011, 9, 791-800. [CrossRef]

27. Kumar, S.; Xie, H.; Scicluna, P.; Lee, L.; Bjornhagen, V.; Hoog, A.; Larsson, C.; Lui, W.O. miR-375 regulation of LDHB plays distinct roles in Polyomavirus-positive and -negative Merkel cell carcinoma. Cancers 2018, 10, 443. [CrossRef]

28. Kumar, S.; Xie, H.; Shi, H.; Gao, J.; Juhlin, C.C.; Björnhagen, V.; Höög, A.; Lee, L.; Larsson, C.; Lui, W.O. Merkel cell polyomavirus oncoproteins induce microRNAs that suppress multiple autophagy genes. Int. J. Cancer 2019. [CrossRef]

29. Daily, K.; Coxon, A.; Williams, J.S.; Lee, C.C.R.; Coit, D.G.; Busam, K.J.; Brownell, I. Assessment of cancer cell line representativeness using microarrays for Merkel cell carcinoma. J. Investig. Derm. 2015, 135, 1138-1146. [CrossRef]

30. Frisch, S.M.; Schaller, M.; Cieply, B. Mechanisms that link the oncogenic epithelial-mesenchymal transition to suppression of anoikis. J. Cell Sci. 2013, 126, 21-29. [CrossRef]

31. Huang, X.Y.; Yuan, T.Z.; Liang, M.H.; Du, M.J.; Xia, S.; Dittmar, R.; Wang, D.; See, W.; Costello, B.A.; Quevedo, F.; et al. Exosomal miR-1290 and miR-375 as prognostic markers in castration-resistant prostate cancer. Eur. Urol. 2015, 67, 33-41. [CrossRef] [PubMed]

32. Su, Y.Y.; Sun, L.; Guo, Z.R.; Li, J.C.; Bai, T.T.; Cai, X.X.; Li, W.H.; Zhu, Y.F. Upregulated expression of serum exosomal miR-375 and miR-1307 enhance the diagnostic power of CA125 for ovarian cancer. J. Ovarian Res. 2019, 12, 6. [CrossRef] [PubMed]

33. Van Gele, M.; Boyle, G.M.; Cook, A.L.; Vandesompele, J.; Boonefaes, T.; Rottiers, P.; Van Roy, N.; De Paepe, A.; Parsons, P.G.; Leonard, J.H.; et al. Gene-expression profiling reveals distinct expression patterns for Classic versus Variant Merkel cell phenotypes and new classifier genes to distinguish Merkel cell from small-cell lung carcinoma. Oncogene 2004, 23, 2732-2742. [CrossRef] [PubMed]

34. Krutzfeldt, J.; Rajewsky, N.; Braich, R.; Rajeev, K.G.; Tuschl, T.; Manoharan, M.; Stoffel, M. Silencing of microRNAs in vivo with 'antagomirs'. Nature 2005, 438, 685-689. [CrossRef]

35. Krutzfeldt, J.; Kuwajima, S.; Braich, R.; Rajeev, K.G.; Pena, J.; Tuschl, T.; Manoharan, M.; Stoffel, M. Specificity, duplex degradation and subcellular localization of antagomirs. Nucleic Acids Res. 2007, 35, 2885-2892. [CrossRef]

36. Xie, J.; Ameres, S.L.; Friedline, R.; Hung, J.-H.; Zhang, Y.; Xie, Q.; Zhong, L.; Su, Q.; He, R.; Li, M. Long-term, efficient inhibition of microRNA function in mice using rAAV vectors. Nat. Methods 2012, 9, 403-409. [CrossRef]

37. Gentner, B.; Schira, G.; Giustacchini, A.; Amendola, M.; Brown, B.D.; Ponzoni, M.; Naldini, L. Stable knockdown of microRNA in vivo by lentiviral vectors. Nat. Methods 2009, 6, 63-66. [CrossRef]

38. Aquino-Jarquin, G. Emerging role of CRISPR/Cas9 technology for microRNAs editing in cancer research. Cancer Res. 2017, 77, 6812-6817. [CrossRef]

39. Chen, Z.; Liu, H.; Yang, H.; Gao, Y.; Zhang, G.; Hu, J. The long noncoding RNA, TINCR, functions as a competing endogenous RNA to regulate PDK1 expression by sponging miR-375 in gastric cancer. Oncotargets 2017, 10, 3353-3362. [CrossRef]

40. Liu, G.; Huang, K.M.; Jie, Z.W.; Wu, Y.Z.; Chen, J.X.; Chen, Z.Z.; Fang, X.Q.; Shen, S.Y. CircFAT1 sponges miR-375 to promote the expression of Yes-associated protein 1 in osteosarcoma cells. Mol. Cancer 2018, 17, 170. [CrossRef]

41. Wang, Y. Upregulated lncRNA-HNGA1, a target of miR-375, contributes to aerobic glycolysis of head and neck squamous cell carcinoma through increasing levels of the glucose transporter protein SCL2A1. Eur. J. Cancer 2016, 61, S14-S15. [CrossRef]

42. Liufu, Z.; Zhao, Y.; Guo, L.; Miao, G.; Xiao, J.; Lyu, Y.; Chen, Y.; Shi, S.; Tang, T.; Wu, C.I. Redundant and incoherent regulations of multiple phenotypes suggest microRNAs' role in stability control. Genome Res. 2017, 27, 1665-1673. [CrossRef] [PubMed]

43. Schrama, D.; Sarosi, E.M.; Adam, C.; Ritter, C.; Kaemmerer, U.; Klopocki, E.; Konig, E.M.; Utikal, J.; Becker, J.C.; Houben, R. Characterization of six Merkel cell polyomavirus-positive Merkel cell carcinoma cell lines: Integration pattern suggest that large $\mathrm{T}$ antigen truncating events occur before or during integration. Int. J. Cancer 2019, 145, 1020-1032. [CrossRef] [PubMed] 
44. Li, J.H.; Liu, S.; Zhou, H.; Qu, L.H.; Yang, J.H. starBase v2.0: Decoding miRNA-ceRNA, miRNA-ncRNA and protein-RNA interaction networks from large-scale CLIP-Seq data. Nucleic Acids Res. 2014, 42, D92-D97. [CrossRef] [PubMed]

45. Agarwal, V.; Bell, G.W.; Nam, J.W.; Bartel, D.P. Predicting effective microRNA target sites in mammalian mRNAs. Elife 2015, 4, e05005. [CrossRef]

46. Zhou, Y.Y.; Zhou, B.; Pache, L.; Chang, M.; Khodabakhshi, A.H.; Tanaseichuk, O.; Benner, C.; Chanda, S.K. Metascape provides a biologist-oriented resource for the analysis of systems-level datasets. Nat. Commun. 2019, 10, 1523. [CrossRef]

47. Subramanian, A.; Tamayo, P.; Mootha, V.K.; Mukherjee, S.; Ebert, B.L.; Gillette, M.A.; Paulovich, A.; Pomeroy, S.L.; Golub, T.R.; Lander, E.S.; et al. Gene set enrichment analysis: A knowledge-based approach for interpreting genome-wide expression profiles. Proc. Natl. Acad. Sci. USA 2005, 102, 15545-15550. [CrossRef]

(C) 2020 by the authors. Licensee MDPI, Basel, Switzerland. This article is an open access article distributed under the terms and conditions of the Creative Commons Attribution (CC BY) license (http://creativecommons.org/licenses/by/4.0/). 